\title{
Reaching out to non-ecologists: why I got involved in wildlife tourism
}

\begin{abstract}
Ronda Green holds a PhD in zoology, and is proprietor of Araucaria Ecotours, adjunct research fellow in Environmental Futures, Griffith University, chair of Wildlife Tourism Australia Inc. and chair of Scenic Rim Wildlife (a branch of Wildlife Queensland). She has conducted research wildlife tourism for the Sustainable Tourism CRC, and also on foraging ecology of birds, effects of habitat modification on wildlife, play behaviour in chimpanzees and seed dispersal by fruit-eating animals, and has over the years worked as university lecturer, environmental consultant, ranger in charge of interpretive activities and manager of a holiday farm. She has published two books, and various chapters and articles in scientific and popular press.
\end{abstract}

I started to get interested in ecotourism many years before the word was coined. Very few of my schoolmates seemed to know or care about the wonderful array of creatures we shared our planet with. I often wondered how anyone could be so bored on so fascinating a planet, and what kinds of experience might lead them to notice its wonders and develop some concern for the conservation of biodiversity (although that word had not yet been coined either, but it's pretty close to what I had in mind). In my last years of high school, I spent a week at a dreadful holiday farm and then a wonderful week at Binna Burra on the edge of Lamington National Park, and started to see the potential of tourism in natural areas with good interpretation as a way of (1) enhancing the enjoyment and understanding of the general public in our fauna and flora and (2) demonstrating that wildlife habitats can have an economic value even if left relatively untouched.

Long story, but my parents agreed to buy a bushland property on which I ran a children's holiday farm for almost three years, with horse-riding, bush-walking, campfire singalongs, treasure-hunts and other games, and a special emphasis on nature studies (including nature-based games, nature treks, a small museum going through the mineral, vegetable and animal kingdoms with a small section on outer space, and an informal natural history and a horsemanship club for children with a regular magazine,).

Although I taught myself zoology to third year university level, plus a lot of botany and geology, and was told by a visiting Mensa member that my little museum alone should be enough to award me first year biology, I gradually realised that to be taken seriously enough to reach more people I needed some kind of formal degree, so started a BSc and ultimately achieved a first-class honours and a $\mathrm{PhD}$ in zoology (both involving foraging ecology and habitat selection by birds). During discussions with other academics I suggested it would be a good idea to introduce environmental issues in a first-year course (which of course is done nowadays) but was told then that it was better left until after a couple of years study of basic science and ecology. I wondered just how we would give clear messages on conservation issues to the world in general if such education was addressed only to third-year ecology students.

I took one year off my doctoral studies to conduct a special project for the Australian Conservation Foundation on opportunities for educational and recreational activities for primary-aged children, during which I also published books on bush holidays in Victoria and guidelines to the preparation of nature trails. I later applied for and was accepted for a lectureship at a tropical tertiary institute that had acquired land for a field study centre, and was disappointed when our new head of department decided not to use this and also could not understand my interest in ecological research on native animals. Other disappointments and conflicts followed, culminating in my resignation in protest.

We decided to start something between a holiday farm and a field study centre, searched for a property within a two-hour drive from Brisbane, with rainforest and permanent water adjacent to a national park, and finally found an 87-acre one at Running Creek, southeast of Rathdowney. As a bonus it harboured platypus and echidna, two species of macropods, regent bowerbirds, squirrel gliders, carpet pythons and other wildlife. For the next few years, while living on the property we called Araucaria because of the tall hoop pines growing naturally there, I worked variously as research associate, casual or part-time lecturer, tutor, seasonal park ranger in charge of interpretive activities, and environmental consultant, and also ran voluntary camps and nature activities in 
Lamington National Park, our home property and other venues for the Gifted and Talented Children's Association, local schools and other groups, in between caring for two small children and a semi-invalid husband.

In 1996 we attended a course on starting and running a business and started ploughing through the red tape necessary for various licences. In May 1997 Araucaria Ecotours ran its first 3-day wildlife tour, giving a kind of mini-course in Australian wildlife groups while visiting a variety of habitats (primarily rainforest, eucalypt forest and wetlands) looking for kangaroos, koalas, platypus, possums, birds, frogs and other wildlife. A few years later we added one-day birdwatching, bushwalking and island tours and changed the route of the 3-day tour to include coastal habitats (mangroves, sandy and rocky shores, and coastal banksia woodland) and a visit to the David Fleay Wildlife Park, where we can see platypus (which don't always oblige by showing themselves in the wild), northern species such as crocodiles and cassowary, and endangered species that are part of conservation breeding projects and very difficult to see in the wild. We still travel this route, and give each of our 3-day tour guests a 40-page custom-written book on Australian wildlife groups with a brief evolutionary and geological history of the continent plus a checksheet for species seen. Birdwatching guests receive a check sheet of possible bird species. We've recently developed a wildlife and forests day-tour to incorporate five of the features we're most often asked about rainforest, waterfalls, kangaroos, koalas and glow worms - plus gentle walks in eucalypt forest and tea-tree wetlands, and searches for birds and other wildlife.

The Southeast Queensland - Northeast New South Wales border regions harbour the third highest biodiversity in Australia and some wonderful scenery, and it is here that most of tours are concentrated. Twice a year (autumn and spring) we also travel way out west to Bowra (an Australian Wildlife Conservancy property long known as a birding hotspot) and Currawinya National Park in the outback, and have also run custom tours from Brisbane to Sydney and elsewhere.

We are gradually building up our Scenic Rim WIldlife Ecology Centre, which takes guests through 500 million years of history of Australia generally and the Scenic Rim in particular, Australian habitats, wildlife in art and science, and local wildlife groups. Nature trails such as the butterfly trail (with food plants for local caterpillars of the five butterfly families, and colour models of caterpillars, pupae and butterflies, with the real insects often fluttering through) and seed dispersal trail (fleshy-fruited trees, shrubs, vines and herbs that are dispersed by various animals) emanating from this. Our rainforest regeneration sites and some aspects of our ecological research on the property will in the future be show-cased also. We are developing a course on wildlife tourism and hope in the future to employ additional guides to run many of our tours while we concentrate more on self-drives visiting the property.

The focus of our tours is always on increasing the understanding and appreciation of our wildlife and the ecosystems they are part of, while ensuring our guests' safety and enjoyment of their holiday. We follow the ideals of ecotourism - nature-focussed, environmentally sound, quality interpretation and contributing to the local community, and have advanced eco-accreditation for all our tours. Our group size is small to minimise our impacts and to be flexible according to interests and needs of our guests, and we demonstrate how to observe animals without disturbing them, use only re-usable plates, cups and cutlery, recycle food scraps as compost, minimise other waste, reduce our carbon footprint by buying local food (and in doing so increase the interest value of meals for our guests), and run our home and wildlife ecology centre on solar panels, which also charge our laptops, spotlights and other equipment, and tell our guests about this. We contribute to the community by buying and hiring locally as much as possible, working in with other tour operations, participating in community events, contributing natural history displays to the local information centre, giving public talks on wildlife, giving complementary tours to locals when spare seats are available, and running local wildlife workshops, wildlife expos and fauna surveys through the Scenic Rim branch of Wildlife Queensland, of which I'm currently chair.

Sometimes things seem to move very slowly, but we have won three tourism awards, but have lacked the time to apply for others over the past few years), received much positive feedback from guests, attracted the attention of a few travel agents and journalists, and have a website, a blog site and a Facebook page which now has over 10,000 'likes.' 
Challenges have largely involved working as a small family company with limited funds, and thus acting simultaneously as guides, marketers (brochure and website development, social media, trade shows etc.), developers of interpretive materials, book-keepers, practical work (weeding, planting for nature trails, cleaning tour vehicle etc.), and everything else that needs doing, which often means we're exhausted after a run of several weeks of tours, and also in the 'slow' times while we try to catch up on all the other work..

Bureaucracy has sometimes slowed us down or made things near-impossible - e.g. the local council not able to tell us what materials would be admissible for holiday cabins, how far they would need to be from the creek etc. unless we first prepared an expensive submission, paid a few extra thousand dollars to submit it, and then wait for a year or so to find out if we could go ahead (I think that process may have been improved since last we checked).

We are also hampered by demands of some agents who would otherwise promote us but insist we should make our tours available every day throughout the year, which would not allow any time for recuperation, attending workshops etc. until we can afford to employ others on a regular basis to run some of the tours for us. Some agents also tell us they are only interested in tours that take 20 or more passengers, or consider we are too specialised to interest many travellers. We have however received a few bookings through agents, have recently been accepted into an international marketing mentoring program run by Tourism Queensland, and are about to run our first-ever tour through an agreement with a cruise company, picking up from the wharf and taking guests birdwatching for the day.

We welcome and actively seek feedback from our guests, including anything they feel could improve the experience, but we get the occasional complaint we consider unreasonable. Since we mostly have to do everything ourselves (from weeding and book-keeping to tour-guiding and website development), and although we are very mindful of hygiene and ensure that food and utensils are not compromised, sometimes we cannot make the tour vehicle as dust-free as we would like between arriving home at night with one group and leaving the following morning with another (we consider getting some sleep in between to be top priority, so we can drive safely), and we have occasional customers who seem excessively fastidious and complain about any slight smudge, or if the lawn at our home property is not completely smooth, the sleeping sheets (if a camping tour) are not properly ironed etc. Others complain if we can't take them spotlighting late into the night and also guide them for birdwatching at dawn (remember my point about sleep, and driving safely? We do offer to leave them with binoculars and a bird-book for their own early birding in those situations) or can't immediately produce all the animals they want to see (we gently remind them that we are seeking wild animals, not visiting a zoo) or allow them to take flashlight photos right into the face of a nocturnal bird. Sometimes these complaints, especially when delivered in pompous tones, can be trying, but fortunately most of our guests are more understanding, and most are really nice people whose company we genuinely enjoy.

All effort has been made to be environmentally sound, except that we still use quite a bit of fossil fuel in transporting our guests. We do have one of the most environmentally sound mini-buses currently available (a Toyota Hi-Ace) and would like to get a hybrid-electric vehicle of similar size when an affordable one comes on the market. Our other major problem is time (or the lack of it). We would like far more time to be available for developing really outstanding and memorable interpretation materials (self-guided nature trails and accompanying fliers and/or audio devices, ebooks, museum displays etc). For this and other reasons we hope to increase business to a point where we can hire guides for many of the tours, and concentrate our own efforts increasingly on developing educational resources at home and via the internet, but still leading some of the tours, including custom or occasional special tours, also mini-courses on natural history themes on the home property. We also hope in the future to be more involved in tourism that includes volunteering in ecological research, and in educational tourism involving schools and universities (domestic and international). I have almost completed an e-book on running wildlife tours, and am developing a short online and face-to-face course around this. We hope to select our future guides from students of this course.

The holiday farm had not been enough to reach the numbers I wanted to (including school-children general populace and politicians), and nor could any small tour company be. I joined the Wildlife Sector of the Sustainable Tourism CRC in some years ago and conducted research on kangaroo 
tourism (fieldwork and questionnaires), birdwatching tourism (questionnaires), effects of wildlife tourism on wildlife (extensive literature survey plus short questionnaires), co-authored a number of reports and participated in Australia's first national conference on wildlife tourism. This led to my being asked to join the committee of a new group, Australian Wildlife Tourism Action Group, and I became vice-chair. The name was a bit of a tongue-twister and I suggested changing to WIldlife Tourism Australia. It was incorporated with this new name and I'm currently chair, and trying to live up to the ideals of the WTA motto of promoting the sustainable development of a diverse wildlife tourism industry which support conservation.

What would I like to see in the future? I've already covered what I would like personally. Worldwide I would like to see more emphasis by tour operators, accommodation-providers, tourism organisations, travel agents and governments on genuine ecotourism rather than the kinds of tourism that might impact negatively on wildlife and habitats, and clear promotion of high-quality low-impact experiences to travellers. I would like to see more travellers actively seeking out such experiences and realising that by paying for such experiences they are adding to economic arguments for the protection of local animals and their habitats (there are many good non-financial reasons for doing so, but the economic arguments can be powerful when negotiating with government and developers).

Most of all I still have hope for a future where the truly wonderful biodiversity of this planet is treasured by the majority of its human inhabitants, and would support any ecotourism venture that nudges things in that direction. 